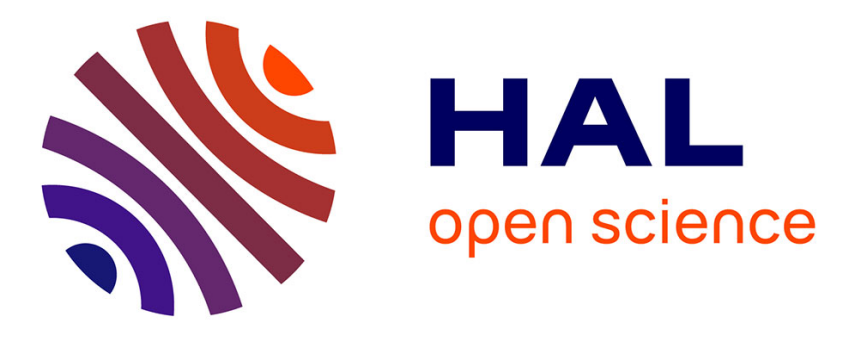

\title{
Hydrogen Silsesquioxane-Based Nanofluidics
}

Sathyanarayanan Punniyakoti, Ragavendran Sivakumarasamy, Francois

Vaurette, Pierre Joseph, Katsuhiko Nishiguchi, Akira Fujiwara, Nicolas

Clément

\section{- To cite this version:}

Sathyanarayanan Punniyakoti, Ragavendran Sivakumarasamy, Francois Vaurette, Pierre Joseph, Katsuhiko Nishiguchi, et al.. Hydrogen Silsesquioxane-Based Nanofluidics. Advanced Materials Interfaces, 2017, 4 (7), pp.1601155. 10.1002/admi.201601155 . hal-01701361

\section{HAL Id: hal-01701361 \\ https://hal.laas.fr/hal-01701361}

Submitted on 5 Feb 2018

HAL is a multi-disciplinary open access archive for the deposit and dissemination of scientific research documents, whether they are published or not. The documents may come from teaching and research institutions in France or abroad, or from public or private research centers.
L'archive ouverte pluridisciplinaire HAL, est destinée au dépôt et à la diffusion de documents scientifiques de niveau recherche, publiés ou non, émanant des établissements d'enseignement et de recherche français ou étrangers, des laboratoires publics ou privés. 


\section{Advanced Materials Interfaces Hydrogen Silsesquioxane-based Nanofluidics \\ --Manuscript Draft--}

Manuscript Number:

Full Title:

Article Type:

Section/Category:

Keywords:

Corresponding Author:

Additional Information:

Question

Corresponding Author Secondary Information:

Corresponding Author's Institution:

Corresponding Author's Secondary Institution:

First Author:

First Author Secondary Information:

Order of Authors:

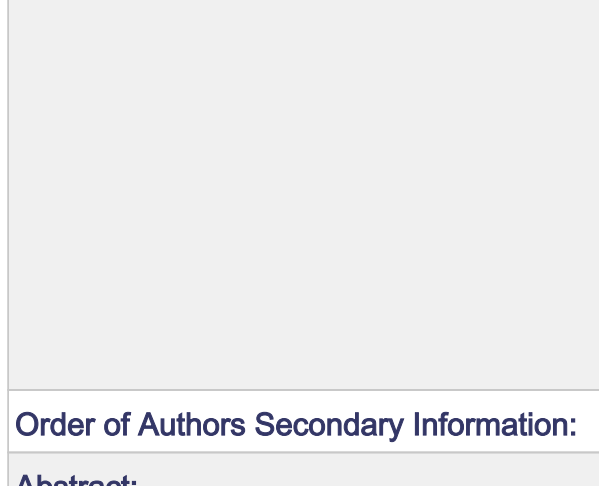

Abstract:
Hydrogen Silsesquioxane-based Nanofluidics

Full Paper

Nanofluidics; HSQ; 3D Nanofluidics; extremely slow evaporation rate

nicolas clement

IEMN-LILLE1

VILLENEUVE D'AS, FRANCE

Response

IEMN-LILLE1

nicolas clement

nicolas clement

Sathya Punniyakoti

Ragavendran Sivakumarasamy

Francois Vaurette

Pierre Joseph

Katsuhiko Nishiguchi

Akira Fujiwara

Nanofluidics show great promise for the control of small volumes and single molecules, especially for biological and energy applications. To build up more and more complex nanofluidics systems, a versatile and reproducible fabrication technique with nanometer precision alignment is desirable. In this article, we present two e-beam lithography methods to fabricate nanofluidic channels based on hydrogen silsesquioxane (HSQ), a high-resolution negative-tone inorganic resist. The robustness and versatility of the fabrication processes are demonstrated on silicon, glass and flexible substrates. The high precision ability is illustrated with nanometric alignment of nanofluidic channels on gold nanoparticles and nanotransistor sensors, as well as for 3D nanofluidics prototyping. Furthermore, we noticed an unexpected extremely slow water evaporation rate ( 1 week for $300 \mu \mathrm{m}$-long nano-channels). This feature enables a simple and reliable manipulation of nanofluidic chips for various studies. 


\section{WILEY-VCH}

DOI: $10.1002 /$ ((please add manuscript number))

Article type: Full Paper

\section{Hydrogen Silsesquioxane-based Nanofluidics}

Sathyanarayanan Punniyakoti, Ragavendran Sivakumarasamy, Francois Vaurette, Pierre Joseph, Katsuhiko Nishiguchi, Akira Fujiwara, and Nicolas Clément*

Dr. S. Punniyakoti, IEMN-CNRS, Avenue Poincaré, 59652, Villeneuve d'Ascq, France; Present address: Centre for Nanotechnology Research, VIT University, Vellore, 632 014, Tamil Nadu, India Dr. R. Sivakumarasamy, Dr. F. Vaurette IEMN-CNRS, Univ. of Lille, Avenue Poincaré, 59652, Villeneuve d'Ascq, France Dr. P. Joseph LAAS-CNRS, Université de Toulouse, CNRS, Toulouse, France

Dr. K. Nishiguchi, A. Fujiwara NTT Basic Research Laboratories, 3-1, Morinosato Wakamiyia, Atsugi-shi, 243-0198, Japan Dr. N. Clément IEMN-CNRS, Univ. of Lille, Avenue Poincaré, 59652, Villeneuve d'Ascq, France and NTT Basic Research Laboratories, 3-1, Morinosato Wakamiyia, Atsugi-shi, 243-0198, Japan

E-mail: nicolas.clement@lab.ntt.co.jp

Keywords: Nanofluidics, HSQ, 3D Nanofluidics, extremely slow evaporation rate

Nanofluidics show great promise for the control of small volumes and single molecules, especially for biological and energy applications. To build up more and more complex nanofluidics systems, a versatile and reproducible fabrication technique with nanometer precision alignment is desirable. In this article, we present two e-beam lithography methods to fabricate nanofluidic channels based on hydrogen silsesquioxane (HSQ), a highresolution negative-tone inorganic resist. The robustness and versatility of the fabrication processes are demonstrated on silicon, glass and flexible substrates. The high precision ability is illustrated with nanometric alignment of nanofluidic channels on gold nanoparticles and nanotransistor sensors, as well as for 3D nanofluidics prototyping. Furthermore, we noticed an unexpected extremely slow water evaporation rate ( 1 week for $300 \mu \mathrm{m}$-long nano-channels). This feature enables a simple and reliable manipulation of nanofluidic chips for various studies. 


\section{WILEY-VCH}

\section{Introduction}

Thanks to its unique features at the nanoscale, nanofluidics, the study and application of fluid flow in nanochannels/nanopores with at least one characteristic size smaller than 100 $\mathrm{nm}$, has enabled the occurrence of many interesting transport phenomena and has shown great potential in both bio- and energy-related fields. ${ }^{[1-5]}$ The unprecedented growth of this research field is related to the rapid development of micro/nanofabrication techniques. Several methods have been developed thus far to afford the fabrication of nanochannels such as optical, e-beam, nanoimprint lithography with sacrificial layers or etching ${ }^{[1,6-10]}$. Another alternative is the use of nanoporous materials. ${ }^{[11,12]}$ Although these different methods are relatively simple, many of them are not compatible with a low-temperature process (e.g. for plastic substrates or organic devices), or do not offer good alignment ability on patterned substrates for rapid prototyping of complex nanofluidic systems (e.g for hybrid nanofluidics/nanosensor devices or 3D nanochannels fabrication).

Si-based inorganic-organic polymers with a general structure of $\left[\mathrm{R}_{\mathrm{x}} \mathrm{SiO}_{\mathrm{y}}\right]_{\mathrm{n}}(\mathrm{R}$ is a hydrocarbon group) have the advantage of being processed at low temperature. However, they cannot be aligned at nanometer scale, and they have a small Young modulus which prevents their use in nanofluidics. Hard PDMS (a PDMS engineered to have a higher mechanical modulus of $\sim 8 \mathrm{MPa}$ ) has been successfully used for nanofluidics, ${ }^{[13,14]}$ but its Young modulus remains small. Polysilsesquioxane (PSQ) has a much higher Young modulus (800 MPa). ${ }^{[15]} \mathrm{It}$ has been successfully used as a simple sealing method, ${ }^{[16]}$ but it cannot be directly prototyped. Finally, Hydrogen Silsesquioxane (HSQ: Fox 16, Dow Corning) can be processed at low temperature, with the high precision alignment provided by e-beam lithography, and provides an additional advantage of planarity. It has often been used in nanoelectronics as a mask before silicon etching thanks to its high resolution $(<10 \mathrm{~nm})$. It can be almost densified to $\mathrm{SiO}_{2}$ after plasma or electron-beam exposition, ${ }^{[17-19]}$ and has also been used for 3D prototyping of photonic crystals ${ }^{[20]}$, or for the fabrication of dielectric nanoantennas ${ }^{[21]}$. 


\section{WILEY-VCH}

However, except its use as a high resolution mold ${ }^{[22]}$ or as channels arising from the collapse of thin HSQ walls, ${ }^{[23]}$ the unique advantages provided by this material have not been exploited to demonstrate a potential use in nanofluidics.

Here, we show that HSQ can be used as a structuring material for nanofluidics applications. We take advantage of the direct HSQ prototyping at nanometer scale and its high planarity to demonstrate two simple and versatile ways of fabricating nanofluidic channels. In particular, we show the possibility to fabricate 3D stacked layers, and to align nanochannels on nanostructured surfaces such as gold nanoparticles or nanotransistor biosensors. Limitations and related solutions specific to the use of HSQ for nanofluidics applications are presented as a guide-line for a practical use of HSQ in nanofluidics. We also evidence an extremely slow evaporation rate of water inside the channels covered by HSQ, an unexpected feature that significantly simplifies microscope studies of chips composed of nanofluidics channels.

\section{Nanofluidic channels fabricated by direct HSQ prototyping (First approach)}

The first approach is based on direct prototyping of HSQ, being used as a negative tone electron beam resist. Technological steps for the proposed approach are summarized in Figure 1a. The starting substrate is an n-type bulk silicon wafer covered with native oxide. If necessary, alignment markers are made using standard photolithography. After substrate dehydration (at $180^{\circ} \mathrm{C}$ for 10 minutes), HSQ is spin-coated to get an 850 -nm-thick layer. Then, the HSQ is exposed to e-beam and developed in tetramethyl ammonium hydroxide (TMAH)$25 \%$ solution for 90 seconds. It is then baked on a hot plate for 30 minutes at $110^{\circ} \mathrm{C}$ followed by 30 minutes annealing at $180^{\circ} \mathrm{C}$ to get robust hydrophilic and transparent nanofluidic channel walls. Using an aligned and patterned Polydimethylsiloxane (PDMS) layer, ${ }^{[24]}$ nanofluidic channels are sealed and the connection to microfluidic channels is established. The distance between walls on access leads has to be small enough (below $3 \mu \mathrm{m}$ ) and sharp 


\section{WILEY-VCH}

enough to avoid bonding of PDMS to the bottom of the channels. On the other hand, at the either ends of the HSQ walls, a smooth slope is required for proper PDMS/HSQ sealing in order to avoid undesired leakage. This 3D prototyping can be achieved by using different ebeam doses within a single writing step (less exposed areas appear thinner after HSQ resist development (see Supplementary Figs.1,2 for more details)). Figure 1b shows a Scanning Electron Microscope (SEM) image of the fabricated HSQ structure composed of parallel large channels with constrictions (nanofluidic channels) and also the smooth slope at the extreme ends of the array. The e-beam writing time was approximately 1 minute and the average roughness on the top of HSQ surface is $0.7 \mathrm{~nm}$. A smooth slope of $10^{\circ}$ on HSQ has been obtained from ten $90 \mathrm{~nm}$-thick, $500 \mathrm{~nm}$-wide stairs obtained from 10 different exposure doses. The average nanofluidic channel width, obtained from 37 channels, is $97 \mathrm{~nm}+/-3.7 \mathrm{~nm}$ (Figure 1c) which highlights the reliability of the proposed technology. Nevertheless, we observe that $15 \%$ of the channels are out of this statistics that we attribute to the high aspect ratio (HSQ thickness vs channel width) required for nanofluidics application. All channels remain within an error of $25 \mathrm{~nm}$ above the average width. There is a tradeoff between the HSQ thickness and the channel width. For example, Grigorescu et al. ${ }^{[18]}$ reported a $10 \mathrm{~nm}$ gap for a 10-nm-thick HSQ (aspect ratio of 1). Such a small layer thickness is well-suited when HSQ is being used as a mask for the nanofabrication purposes. It is however not compatible with the present HSQ-based nanofluidics, mainly because PDMS can partly bind to the bottom of the channel in the 2 or $3 \mu \mathrm{m}$ access leads. This is illustrated in Supplementary Fig.3 for a 300-nm-thick HSQ layer. We found that $400 \mathrm{~nm}$ can be considered as a minimum thickness and $850 \mathrm{~nm}$ a good tradeoff for high resolution, high reliability (no PDMS bonding in the channel), and reduced pressure drop (3- $\mu \mathrm{m}$-wide access leads can be used at this HSQ layer thickness). We also noticed that there is no major difference in channel width resolution between $400 \mathrm{~nm}$ and $850 \mathrm{~nm}$ thick HSQ channels. Our best result with a 850 -nm-thick HSQ layer is $74 \mathrm{~nm}$ (aspect ratio of 12, see Supplementary Fig.4). If a smaller gap is required for 


\section{WILEY-VCH}

some applications (at high ionic strength, a 100-nm-wide nanochannel becomes too large compared to the Debye screening length), this can be achieved by using atomic layer deposition (ALD) (see Supplementary Fig.5 for channel width reduction by $\mathrm{Al}_{2} \mathrm{O}_{3}$ ALD). This combined HSQ/ALD approach is also promising for the development of vertical nanofluidics transistors as Pt can also be deposited by ALD (Supplementary Fig.5).

Figure 2 illustrates the versatility of the technique with three different substrates: silicon, glass slide and flexible polyethylene naphthalate (PEN) respectively. On silicon substrates, in complement to Figure 1, Figures $2 \mathrm{a}, 2 \mathrm{~b}$ and $2 \mathrm{c}$ show the HSQ patterned area (150 $\mu \mathrm{m}$ large and $300 \mu \mathrm{m}$ long), the PDMS-sealed nanofluidics channels before water filling, and the different stages of water filling under a given pressure of 3 bars. It confirms that nanofluidic channels can be successfully operated with this technology. Although difference in filling times (up to tens of seconds) is observed, all channels can be filled under the same pressure, which is consistent with the small dispersion in channel widths observed by SEM. The process can be transposed to other substrates by simply evaporating a thin layer of Germanium ( $\sim \mathrm{nm}$ ) on top of the HSQ before e-beam lithography so as to evacuate charges. After exposure, the germanium layer was removed with a 1:1 solution of $\mathrm{H}_{2} \mathrm{O}_{2}: \mathrm{H}_{2} \mathrm{O}$ during $\sim 1 \mathrm{~min}$. Then, the process is the same as on silicon. Figure 2d, 2e and 2f show HSQ patterned areas on a glass slide and the complete filling of fluorescent marked DNA molecules inside the nanofluidic channels. ${ }^{[14,25]}$ Figure $2 \mathrm{~g}$ and $2 \mathrm{~h}$ indicate that similar results can also be obtained on a flexible substrate. In that particular case, the flexible substrate was first fixed on silicon substrate by mean of a droplet of PDMS prior spin coating.

\section{Fabrication of nanochannels with extremely slow evaporation rate by direct prototyping of AZnLof and HSQ resists (Second approach)}




\section{WILEY-VCH}

We also propose a second HSQ-based approach using the conventional sacrificial layer method (see Figure 3). These sacrificial layers are usually either metal layers ${ }^{[26-30]}$ or positive resists like PMMA ${ }^{[8]}$ and both of these have some drawbacks. The former one involves removal of metal layers at the end of the process which is usually difficult and requires few hours. ${ }^{[31,32]}$ The later one involves writing of large areas, which is not the optimum solution. Recently, it was demonstrated that AZnLof, usually used for optical lithography, could also be patterned by e-beam with very high resolution. ${ }^{[33]}$ We spin-coated $100 \mathrm{~nm}$-thick diluted resist AZnLof 2020 in PGMEA (1:3 ratio), and defined nanochannels by e-beam, prior to HSQ deposition (Figure 3a). Both lateral and vertical dimensions can be set down to $\sim 100 \mathrm{~nm}$ (Figure $3 \mathrm{~b}$ ). We noticed that an annealing step at $170^{\circ} \mathrm{C}$ enabled optimization of the resist roughness leading to a perfect half-cylinder (Figure 3b). After HSQ deposition and baking, a piranha solution $\left(\mathrm{H}_{2} \mathrm{SO}_{4} / \mathrm{H}_{2} \mathrm{O}_{2}: 2 / 1\right)$ was used to dissolve and remove the embedded $\mathrm{AZnLof}$ resist by gentle agitation ( $50 \mathrm{rpm}$ ) for 30 minutes, leaving channels with clean and smooth inner surfaces. The remaining piranha in the channels was replaced finally by DI water rinse under agitation. The advantages of HSQ to make the channel rather than other deposition methods such as sputtering, are to take advantage of its planarity and get rid of extra lithography and etching steps that can be complicated, in particular on patterned surfaces. It will be illustrated in the next section. We also experienced a difficulty for removing the AZnLof layer when it is covered with another oxide such as an $\mathrm{Al}_{2} \mathrm{O}_{3}$ deposited by ALD before HSQ deposition.

Interestingly, we noticed that water in the channels remained for at least one week without noticeable evaporation with inlets/outlets open to air as presented in Figure 3c ( no PDMS bonding in this approach); whereas in the first approach with direct HSQ prototyping, the complete evaporation was observed in few minutes. These experiments have been performed in clean room at a fixed temperature of $21^{\circ} \mathrm{C}$ and a humidity ratio of approximately $50 \%$. It was previously shown that roughness or section shape (square vs circular) plays a 


\section{WILEY-VCH}

critical role in the evaporation in microfluidic channels, ${ }^{[34-40]}$ and consensus seems to have been reached that surface cleanliness plays an important role. ${ }^{[41]}$ However, typical evaporation times in micro- or nano- fluidic channels are in the minute range ${ }^{[34-42]}$ (or in the range of mm per minute), which is more than 4 orders of magnitude faster than in the present study. Sole consideration of the steady-state vapor diffusion governed by the Laplace equation ${ }^{[43]}$ should lead to evaporation times in the second or minute range with or without consideration of evaporation-induced cavitation effects. ${ }^{[37]}$ The present structure has a small roughness which may increase the evaporation time as already discussed in the literature, ${ }^{[34]}$ but cannot fully explain the extremely slow evaporation rate observed. A full understanding of the underlying mechanisms requires a dedicated experimental and theoretical study as in refs. ${ }^{[37,44]}$. We suggest that the experimentally observed slow evaporation rate could be related either to the absence of impurities due to the non-exposure to air, or to an hydrophobic/hydrophilic transition at nanofluidic channels inlets/outlets ${ }^{[45,46]}$ (HSQ hydrophobicity depends on the ebeam dose $\mathrm{e}^{[22]}$ which is expected to be weaker at channel ends), or eventually to nanoporosity in HSQ. This extremely slow evaporation rate is of practical interest to simplify setups for microscopy experiments (see Figure.3d showing a fluorescent image of nanofluidic channels filled with marked DNA).

\section{3D Nanofluidics and nanometric precision alignment}

In a similar manner as for the fabrication of photonic crystals, ${ }^{[20]}$ the good alignment ability and the unique planarity provided by HSQ, enable to stack these layers together to make 3D nanofluidic channels (Figure 4a and 4b), a key step for highly integrated and multiplexed nanofluidics. It was achieved here by repeating AZnLof patterning and HSQ deposition. Figure 4b, inset, shows two levels of channels with interconnect openings (vias) between the top and bottom layers, and the planar upper surface of the HSQ layer (images of the various steps are shown in Supplementary Fig.6. Vias were achieved by performing e-beam 


\section{WILEY-VCH}

lithography on PMMA resist (5\% 950K, $3 \mu \mathrm{m}$-thick) prior to reactive ion etching of HSQ by $\mathrm{CF}_{4} / \mathrm{CHF}_{3}$ plasma. Several design rules have to be respected for HSQ-based 3D nanofluidics.

A thin HSQ layer is required because of the non-uniform reactive plasma etching rate between vias centers and sides, which render difficult the uniform etching down to the 100 nm-thick underlayer of AZnLof (Supplementary Fig.7a,b). An optimum HSQ-layer thickness $(\approx 500 \mathrm{~nm})$ was selected based on the observation that nanofluidic channels collapse, either during HSQ baking or during AZnLof removal, for HSQ layer thicknesses below $400 \mathrm{~nm}$ (Supplementary Fig.7b). This effect is channel-width dependent. In particular, for channels wider than $4 \mu \mathrm{m}$, channels are systematically collapsed, independently on the HSQ layer thickness. In the 500-nm-thick HSQ layer configuration, 500-nm-wide vias could be achieved. Smaller vias (e.g. $200 \mathrm{~nm}$ or smaller), require significant optimization of the etching rate and suffer from reproducibility. Larger vias affect the uniformity of the second layer of AZnLof that partly falls into the via (Supplementary Fig.7), and results in a clogged hole after the deposition of a second layer of HSQ. With these design rules in mind, the process is very robust and reproducible.

Although some previous reports have successfully shown the possibility of 3D nanofluidics ${ }^{[47-49]}$, the degree of control/precision proposed with HSQ-based nanofluidics (channels crossing) brings new perspectives toward well controlled large-scale integrated nanofluidics or hybrid devices. When the surface is initially patterned, the combination of nanometric precision alignment and planarity are required. For example, single-crystal $\mathrm{Au}$ nanoparticules (fabricated by e-beam lithography and thermal annealing), or nanoscale transistor sensors, have been successfully used in the fields of molecular electronics ${ }^{[50-53]}$ electrochemistry ${ }^{[53,54]}$ and single-molecule or single-charge-sensitive biosensors ${ }^{[55-57]}$. Nanofluidics could be a very attractive approach to provide an upper electrode made of liquid metal $^{[58]}$ for high-frequency molecular electronics ${ }^{[53]}$, to reduce parasitic capacitance in nanoelectrochemistry, or simply to focus analytes on top of nanoscale biosensors. Figure 5 


\section{WILEY-VCH}

shows the ability to fabricate such structures on Au nanoparticles and $50 \mathrm{~nm}$-thick nanoscale

transistor biosensors without any further complexity arising from the patterned surfaces.

\section{Conclusion}

We proposed the demonstration of a well-controlled and versatile technique for the fabrication of nanofluidic channels with nanometric precision alignment based on HSQ. The first approach requires only a single, small area writing step, and enables nanometric precision alignment. In the second approach, a conventional sacrificial layer approach was exploited for the fabrication of $\sim 100 \mathrm{~nm}$ diameter half-pipe HSQ nanofluidics channels together with nanometric precision alignment and 3D nanofluidics demonstration. The proposed reliable approaches provides a pathway for the development of more and more complex nanofluidic systems including the interfacing of nanofluidics with nanoscale sensors, while the extremely slow evaporation rate brings simplicity for the characterizations or applications and new perspectives for basic research in nanofluidics.

\section{Experimental Section}

\section{Si mold:}

S1818 resist (Microposit@) was spin-coated at $2500 \mathrm{rpm}$ with an acceleration of $1000 \mathrm{rpm}$ for $12 \mathrm{~s}$. Silicon was etched using reactive ion etching (RIE). The gases used for the RIE process was $\mathrm{SF}_{6}$ and $\mathrm{O}_{2}$ and the gas used for passivation was $\mathrm{C}_{4} \mathrm{~F}_{8}$. The flow rates of $\mathrm{SF}_{6}$, $\mathrm{O}_{2}$, and $\mathrm{C}_{4} \mathrm{~F}_{8}$ were 450,45 , and 100 standard $\mathrm{cm}^{3}$ per minute ( $\mathrm{sccm}$ ), respectively. The coil power was $1000 \mathrm{~W}$. RIE had an approximate etch rate of $4 \mu \mathrm{m} / \mathrm{min}$. After etching the wafers, we examined the microstructures on the wafers by optical microscopy. We stripped the remaining photoresist from the silicon wafer by immersing the wafer in EKC 265 at $60^{\circ} \mathrm{C}$ for $30 \mathrm{~min}$, followed by immersion in acetone and isopropanol for $5 \mathrm{~min}$ each. 


\section{WILEY-VCH}

\section{PDMS Layer Fabrication (For method 1):}

A thin layer of PDMS (thickness: $200 \mu \mathrm{m}$ ) was required for the alignment protocol and for precisely defining the holes for tubing. The uncured PDMS (mixing ratio of curing agent/ base ratio: 1/3) was spin-coated at $300 \mathrm{rpm}$ for $30 \mathrm{~s}$, with an acceleration rate of $100 \mathrm{rpm} / \mathrm{s}$. It was then cured in two steps: (i) at $65^{\circ} \mathrm{C}$ for $20 \mathrm{~min}$ in contact with a hot plate and (ii) in a convection oven at $120^{\circ} \mathrm{C}$ for $40 \mathrm{~min}$.

\section{Alignment and Bonding (For method 1):}

Prior to bonding, the Si chip and PDMS layer were exposed to $\mathrm{O}_{2}$ plasma $(120 \mathrm{~W}, 0.7 \mathrm{mbar}$, $180 \mathrm{~s}$ ) and to UV-ozone for $5 \mathrm{~min}$. After proper alignment and bonding with $1-\mu \mathrm{m}$ alignment precision, ${ }^{[24]}$ thermal annealing was performed at $120^{\circ} \mathrm{C}$ for $60 \mathrm{~min}$.

A second layer of PDMS (2 mm in thickness) was used to guide the tube and reduce the mechanical stress at the inlet and outlet. Access holes for connecting the inlet and outlet tubes (PTFE tubing: $0.7 \mathrm{~mm} / 0.3 \mathrm{~mm}$ outer diameter [OD]/inner diameter [ID]) were cored into the 2-mm-thick PDMS by using a 300- $\mu \mathrm{m}$-ID needle, with an approximate distance between the two holes of less than $1 \mathrm{~mm}$.

\section{Supporting Information}

Supporting Information is available from the Wiley Online Library.

\section{Acknowledgements}

The authors would like to thank P. Tilmant and Y.Viero for discussions, D. Troadec for FIB cross sections, and the CPER CENIA for funding of S. Punniyakoti's post-doc and the SINGLEMOL project from Nord Pas de Calais council for funding the process work. This work was partially funded by the RENATECH network.

Received: ((will be filled in by the editorial staff))

Revised: ((will be filled in by the editorial staff)) Published online: ((will be filled in by the editorial staff)) 


\section{WILEY-VCH}

[1] D. Xia, J. Yan, and S. Hou, Small 2012, 8, 2787.

[2] W. Reisner, K. J. Morton, R. Riehn, Y. M. Wang, Z. Yu, M. Rosen, J. C. Sturm, S. Y. Chou, E. Frey, and R. H. Austin, Phys. Rev. Lett., 2005, 94, 196101.

[3] X. Liang, K. J. Morton, R. H. Austin, and S. Y. Chou, Nano Lett., 2007, 7, 3774.

[4] W. Guo, L. Cao, J. Xia, F.-Q. Nie, W. Ma, J. Xue, Y. Song, D. Zhu, Y. Wang, and L. Jiang, Adv. Funct. Mater., 2010, 20, 1339.

[5] D. Gillespie, Nano Lett., 2012, 12, 1410.

[6] J.M. Perry, D. Harms and S.C. Jacobson, Small, 2012, 8, 1521.

[7] C. Duan, W. Wang, and Q. Xie, Biomicrofluidics, 2013, 7, 026501.

[8] F. Güder, Y. Yang, M. Krüger, G. B. Stevens, and M. Zacharias, ACS Appl. Mater. Interfaces., 2010, 2, 3473.

[9] Y. Wu, J. Zhou and E. Y. B. Pun, J. MicroNanolithography MEMS MOEMS, 2011, 10, 049701.

[10] P. Abgrall and N. T. Nguyen, Anal. Chem., 2008, 80, 2326.

[11] D. Xia and S. R. J. Brueck, J. Vac. Sci. Technol. B, 2005, 23, 2694.

[12] D. Xia, T. C. Gamble, E. A. Mendoza, S. J. Koch, X. He, G. P. Lopez, and S. R. J. Brueck, Nano Lett., 2008, 8, 1610.

[13] H. Schmid and B. Michel, Macromolecules, 2000, 33, 3042.

[14] Q. Hao, Q. He, H. Ranchon, P. Carrivain, Y. Viero, J. Lacroix, C. Blatche, E. Daran, J.-M. Victor, and A. Bancaud, Macromolecules, 2013, 46, 6195.

[15] N. Takamura, T. Gunji, H. Hatano, and Y. Abe, J. Polym.Sci.Part.A.Polym.Chem., 1999, 37, 1017.

[16] H. Namatsu, Y. Takahashi, K. Yamazaki, T. Yamaguchi, M. Nagase, and K. Kurihara, J. Vac. Sci. Technol. B, 1998, 16, 69.

[17] J. Gu, R. Gupta, C.-F. Chou, Q. Wei, and F. Zenhausern Lab.Chip., 2007, 7, 1198. 


\section{WILEY-VCH}

[18] A. E. Grigorescu, M. C. van der Krogt, C. W. Hagen, and P. Kruit, Microelectron. Eng., 2007, 84, 822.

[19] Y. Guerfi, J.B. Doucet, and G. Larrieu, Nanotechnology, 2015, 26, 425302.

[20] L. T. Varghese, L. Fan, J. Wang, Y. Xuan, and M. Qi, Small, 2013, 24, 4237.

[21] P.R. Wiecha, A. Arbouet, C. Girard, A. Lecestre, G. Larrieu and V. Paillard, Nat.Nano., 2016, doi://10.1038/nnano.2016.224

[22] J.A. van Kan, C.Z. Zhang, P.P. Mador, and J.R.C. van der Maarel, Biomicrofluidics, 2012, 6, 036502.

[23] S. Choi, M. Yan, and I. Adesida, Appl.Phys.Lett., 2008, 93, 163113.

[24] R. Sivakumarasamy, K. Nishiguchi, A. Fujiwara, D. Vuillaume and N. Clement, Anal.Methods, 2014, 97, 6.

[25] W.Reisner, J.P.Beech, N.B. Larsen, H. Flyvbjerg, A. Kristensen, J.O. Tegenfeldt, Phys.Rev.Lett., 2007, 99, 058302.

[26] G. J. Cheng, D. Pirzada, and P. Dutta, J. MicroNanolithography MEMS MOEMS, 2005, 4, 013009.

[27] H. Zeng, Z. Wan, and A. D. Feinerman, Nanotechnology, 2006, 17, 3183.

[28] J. C. T. Eijkel, J. Bomer, N. R. Tas, and A. van den Berg, Lab. Chip, 2004, 4, 161.

[29] K. P. Nichols, J. C. T. Eijkel, and H. J. G. E. Gardeniers, Lab. Chip, 2007, 8, 173.

[30] W. Sparreboom, J. C. T. Eijkel, J. Bomer, and A. van den Berg, Lab. Chip, 2008, 8, 402.

[31] N. R. Tas, P. Mela, T. Kramer, J. W. Berenschot, and A. van den Berg, Nano Lett., 2003, 3, 1537.

[32] R. Müller, P. Schmid, A. Munding, R. Gronmaier, and E. Kohn, Diam. Relat. Mater., 2004, 13, 780 .

[33] E. Herth, P. Tilmant, M. Faucher, M. François, C. Boyaval, F. Vaurette, Y. Deblocq, B. Legrand, and L. Buchaillot, Microelectron. Eng., 2010, 87, 2057. 
[34] F. Chauvet, P. Duru, S. Geoffroy, and M. Prat, Phys.Rev.Lett, 2009, 110, 124.

[35] J.B. Laurindo and M. Prat, Chem.Eng.Sci., 1998, 53, 2257.

[36] J.C.T. Eijkel et al., Phys.Rev.Lett., 2005, 95, 256107.

[37] M. Prat et al., Int.J.Heat.Mass.Transp., 2007, 50, 1455.

[38] C. Duan, R. Karnik, M.-C.Lu, and A. Majumdar, PNAS, 2012, 109, 3688.

[39] J. Lee, T. Laouiard, R. Karnil, Nat.Nano, 2014, 9, 317.

[40] P. Joseph, et al., MicroTAS, 2010, Groningen, the Netherlands.

[41] J.C.T. Eijkel, and A. van den Berg, Lab.Chip., 2005, 5, 1202.

[42] H.J. Crabtree, et al., Anal.Chem, 2001, 73, 4079.

[43] R.D. Deegan et al., Nature, 1997, 389, 827.

[44] K. Roger, M. Liebi, J. Heimdal, Q.D. Pham, and E. Sparr, PNAS, 2016, 113, 10275.

[45] N. Shokri, P. Lehman and D.Or, Geophys.Res.Lett., 2008, 35, L19407.

[46] S.Yu et al, Sci.Rep., 2015, 5, 13600.

[47] R.Sordan et al, Lab.Chip., 2009, 9, 1556.

[48] S.Jeon et al, Nanolett., 2005, 5, 1351.

[49] S.Liao et al, Lab.Chip., 2013, 13, 1626.

[50] N.Clement, G. Patriarche, K. Smaali, F. Vaurette, K. Nishiguchi, D. Troadec, A. Fujiwara and D. Vuillaume, Small, 2011, 7, 2607.

[51] K.Smaali, et al., ACS Nano, 2012, 6, 4639.

[52] K.Smaali, et al., Nanoscale, 2015, 7, 1809.

[53] J. Trasobares, et al., Nat.Commun., 2016, 7, 12850.

[54] N.Clement, et al., Nanolett., 2013, 13, 3903.

[55] H.Cai, et al., ACS Nano., 2016, 10, 4173.

[56] N.Clement, et al., Appl.Phys.Lett., 2011, 98, 014104.

[57] R. Sivakumarasamy et al., Selective-layer-free Blood Ionogram using a Nanoscale Silicon Transistor that breaks the Boltzmann ion distribution 
WILEY-VCH

[58] C.A. Nijhuis et al., Nanolett., 2010, 10, 3611. 


\section{WILEY-VCH}

a

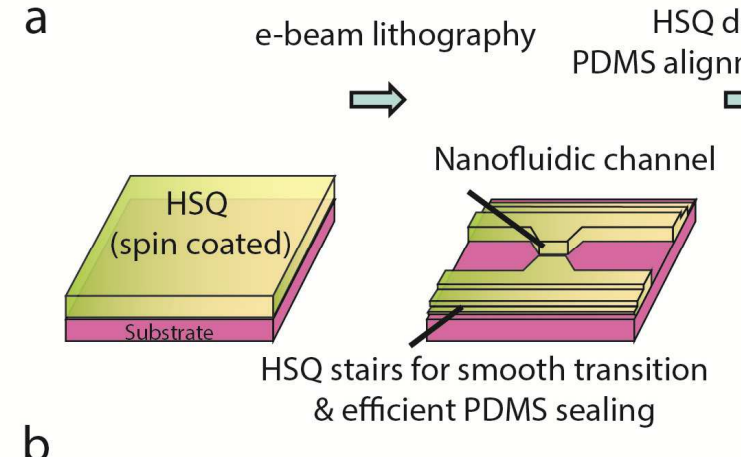

b

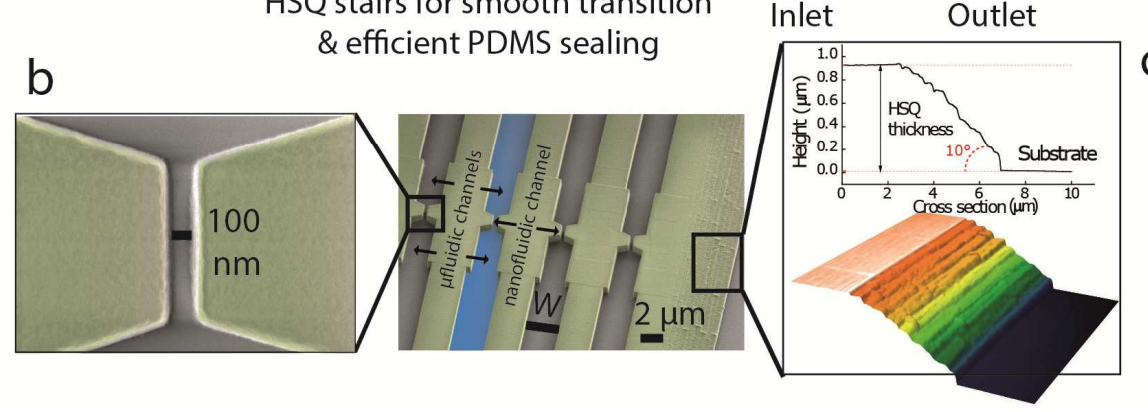

HSQ densification,

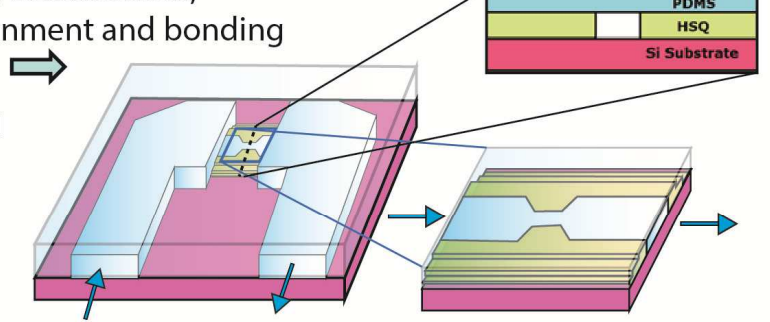

Outlet

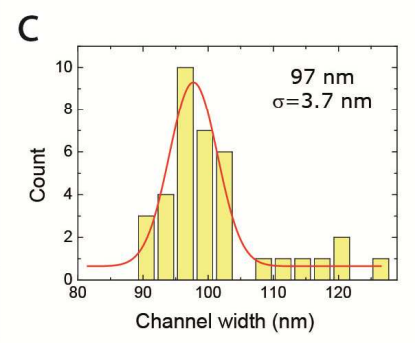

Figure 1. HSQ-based nanofluidics with direct HSQ patterning and PDMS bonding (a) Schematic view of the HSQ-based fabrication process. $850 \mathrm{~nm}$-thick HSQ is first spincoated. HSQ walls and stairs are written within a unique and short e-beam lithography step (typically $1 \mathrm{~min} / \mathrm{chip}$ ). HSQ is baked on a hot plate for $30 \mathrm{~min}$ at $110^{\circ} \mathrm{C}$, followed by $30 \mathrm{~min}$ at $180^{\circ} \mathrm{C}$ and the PDMS microfluidic channel is then aligned and bonded.( b) Scanning Electron Microscope (SEM) top views of the HSQ nanochannels and Atomic Force Microscope topography image of HSQ stairs with a cross section. Channel width W is $3 \mu \mathrm{m}$ at inlets and outlets and below $100 \mathrm{~nm}$ at the nanoconstriction that defines the nanofluidic channel. (c) Histogram of nanofluidic channel width measured by SEM for 37 channels. Average width is $97 \mathrm{~nm}$ with a standard deviation $\sigma=3.7 \mathrm{~nm}$. 


\section{WILEY-VCH}
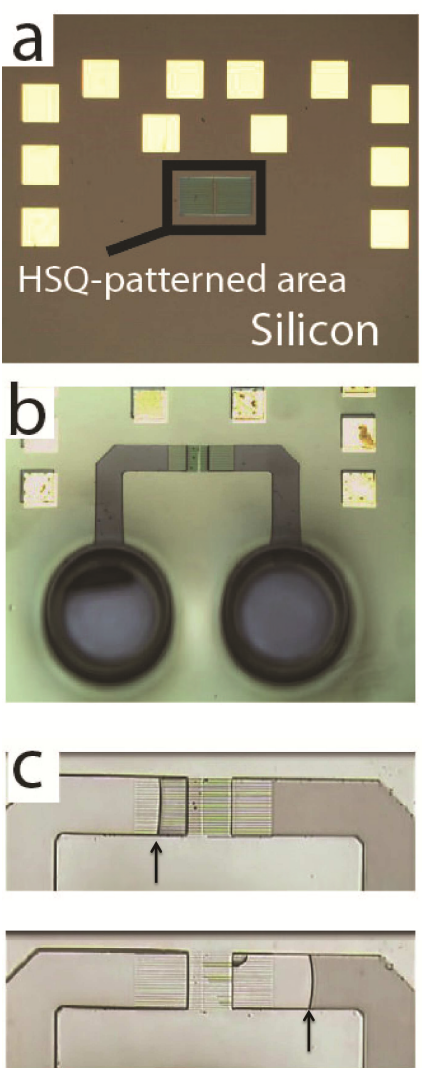
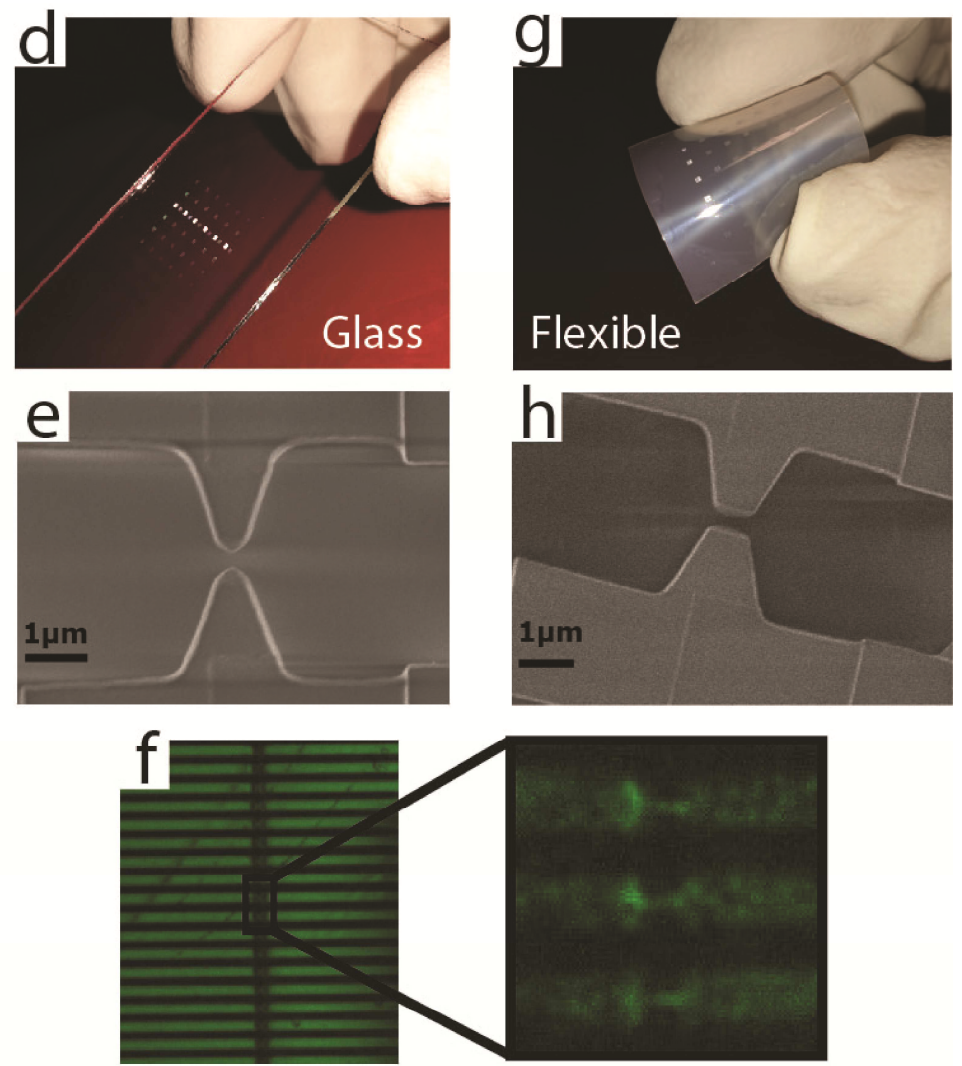

\section{Figure 2. Versatility of HSQ-based nanofluidics}

(a- c) Silicon substrate: (a) Optical image showing the HSQ-patterned area. (b) Microfluidic channels aligned on the HSQ patterned area to form a microfluidic/nanofluidic transition.( c) Demonstration of flow of DI water in the nanofluidic channels (water progress and the direction of the flow are indicated by an arrow). Transparent color corresponds to filled channels. Applied pressure was 3 bars. (d-f) HSQ-based nanofluidics on glass substrate: (d) Picture of the glass slide with HSQ-patterned areas. (e) SEM image of the HSQ nanoconstriction. (f) Confocal microscope image of the nanofluidic channels filled with Alexa-marked 25 ss-DNA. (g-h) HSQ-based nanofluidics on flexible substrate: (g) Picture of the flexible substrate with HSQ-patterned areas. (h) SEM image of the HSQ nanoconstriction. 


\section{WILEY-VCH}
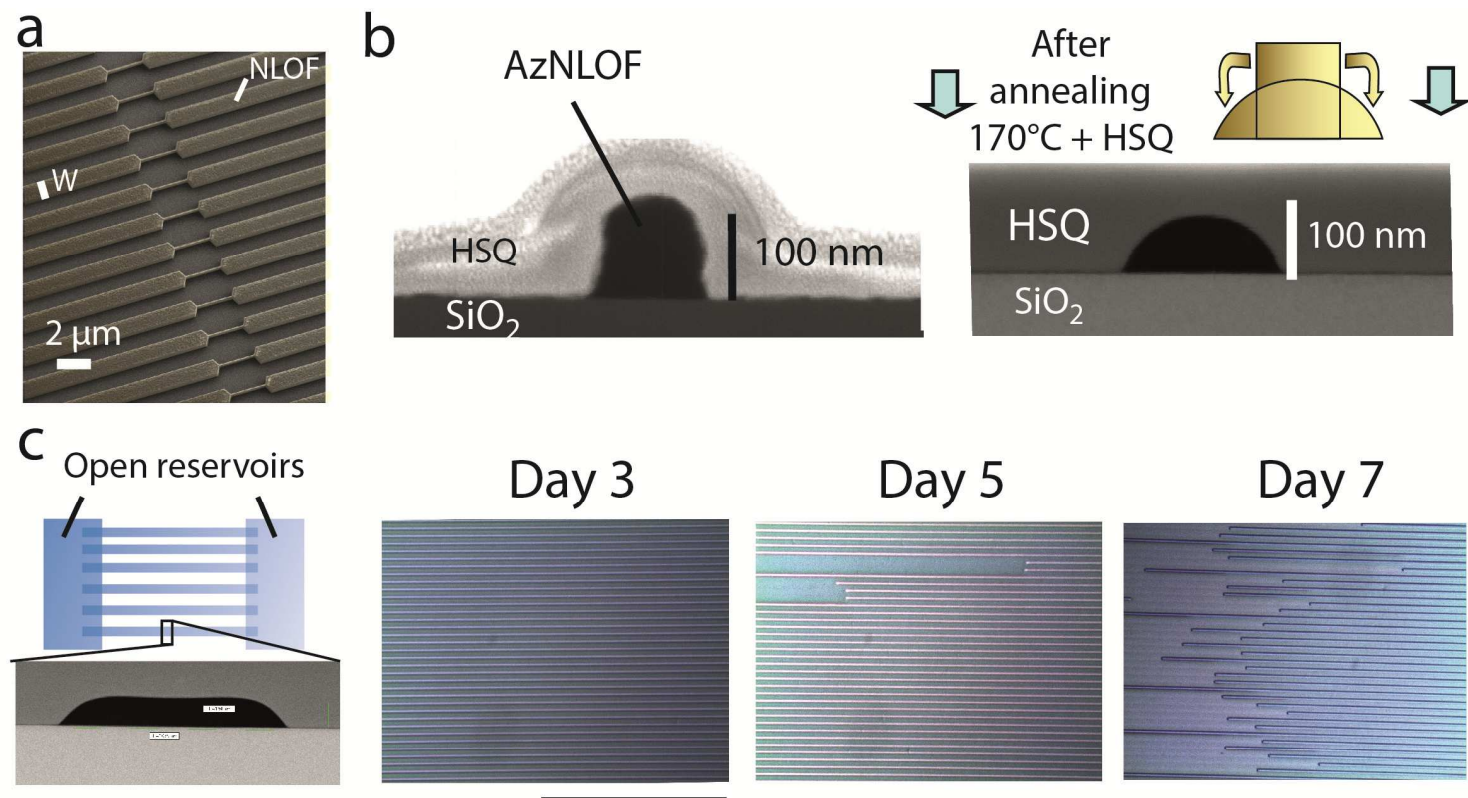

$50 \mu \mathrm{m}$

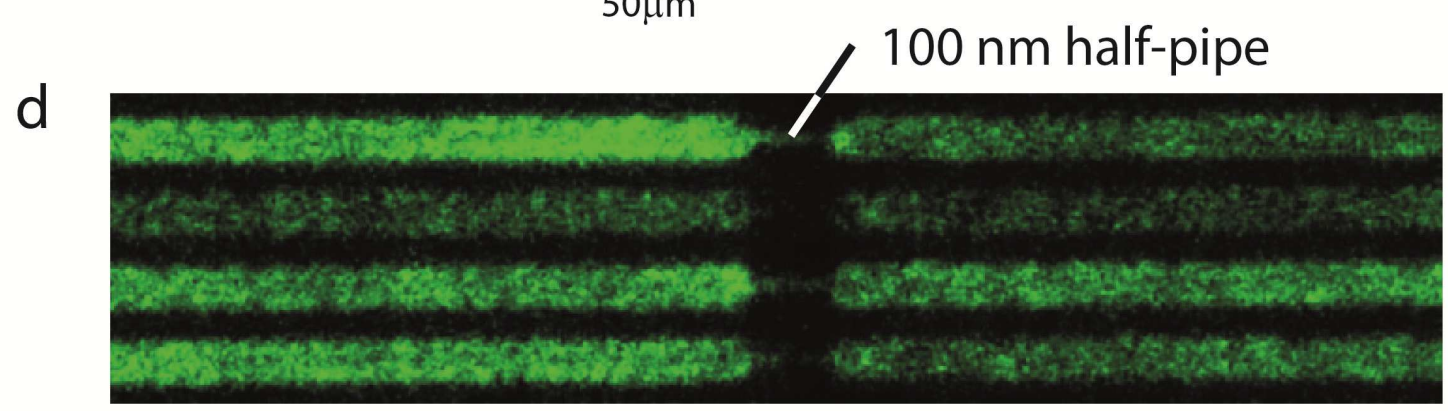

Figure 3. HSQ-based nanofluidics with sacrificial layer approach

(a) SEM image (top view) of the AZnLof sacrificial layer. (b) Cross sectional SEM image of nanochannels before annealing (left) and after the complete process including sacrificial layer removal (right). (c) Study of the evaporation rate. Left: schematic view of the nanofluidic channels ( $3 \mu \mathrm{m}$ wide, $100 \mathrm{~nm}$ thick) nanofluidic channels with open reservoirs. The related cross-section SEM image is shown below. Right: Optical images of the nanofluidic channels showing the extremely slow evaporation rate over 1 week $(<1 \mathrm{fL} / \mathrm{h}$ starting after day 4$)$. The pictures have not been taken on the structure center (slightly on the left) for showing evaporation coming only from the sides. (d) Confocal microscope image of ss-DNA marked with Alexa fluorophore. 
WILEY-VCH

a

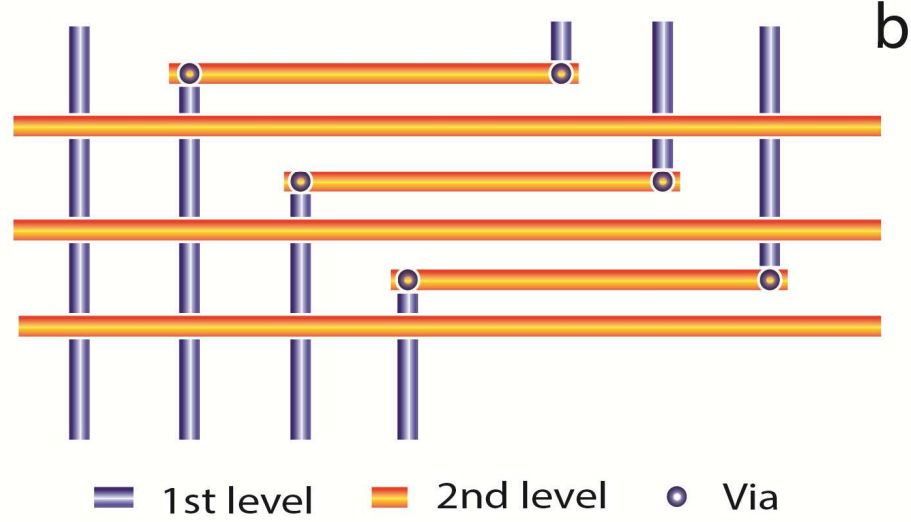

b

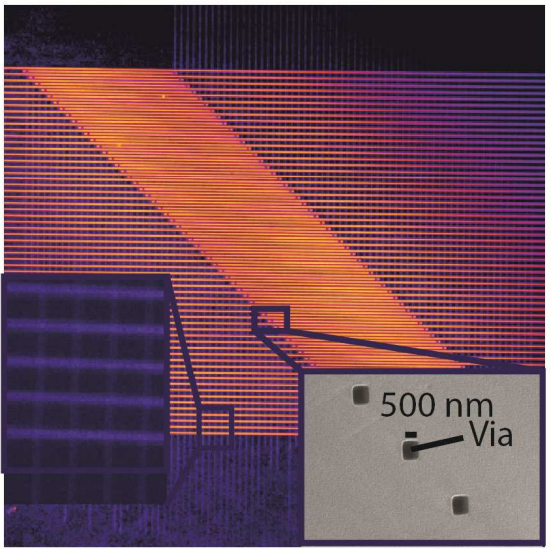

\section{Figure 4. 3D HSQ-based nanofluidics}

a) Schematic representation of the 3D nanofluidics structure. b) Related confocal microscope image of the 3D nanofluidics channels with ss-DNA marked with Alexa fluorophore. Insets: SEM image of the vias used for the 3D nanofluidics channels. 


\section{WILEY-VCH}
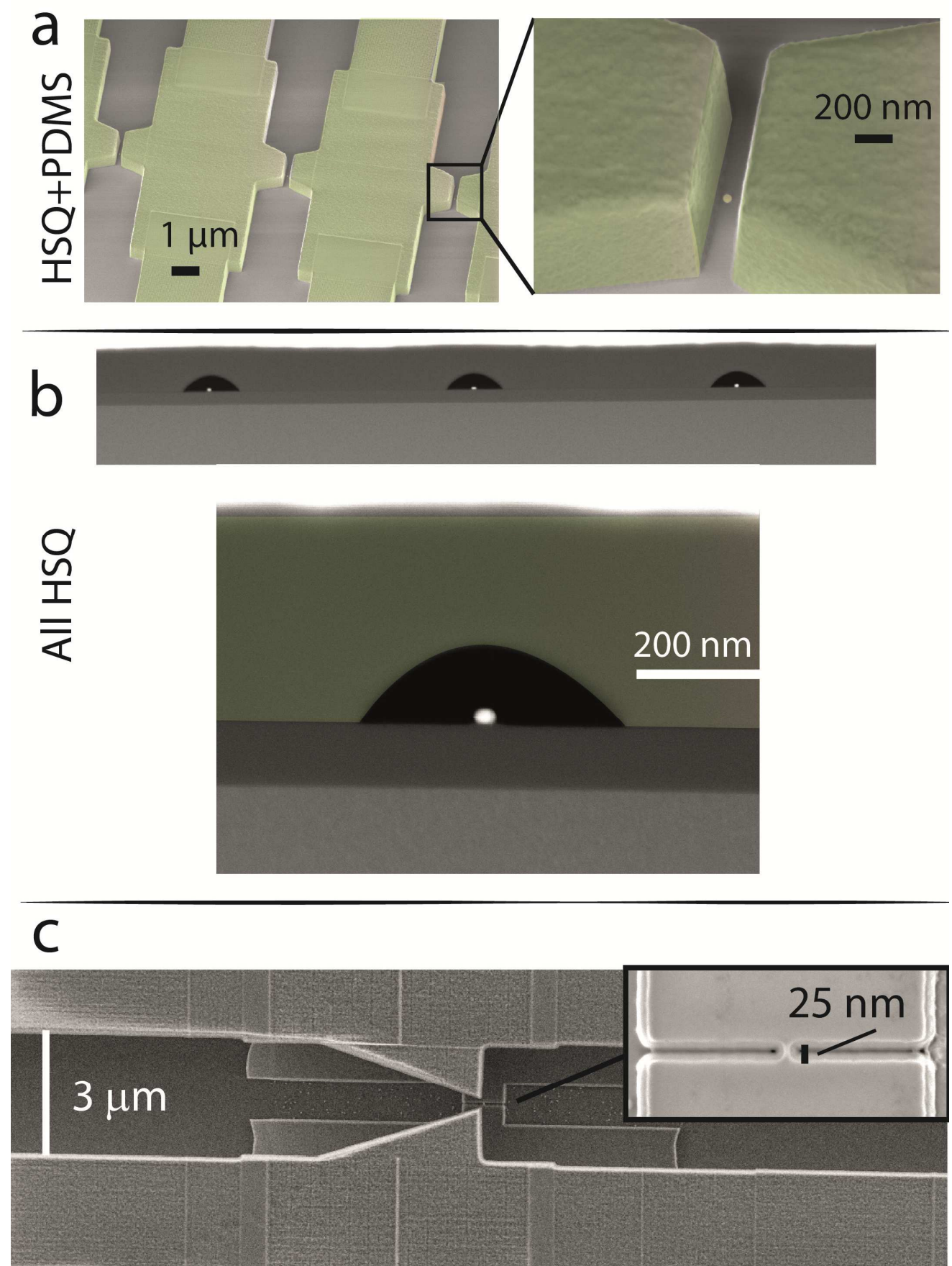

Figure 5. Nanochannels with nanometric alignment precision ability

a) SEM image of the nanofluidics channels aligned on $20 \mathrm{~nm}$-large gold nanodot (fabricated with the direct patterning of HSQ). b) SEM cross section images of nanofluidics channels fabricated with the sacrificial layer approach with precisely aligned gold nanoparticles. c) SEM top view of an HSQ-based nanofluidic channel aligned on a patterned surface, namely a nanoscale transistor biosensor. Inset: SEM image of the nanoscale transistor biosensor. 
WILEY-VCH

Hydrogen Silsesquioxane-based Nanofluidics

ToC figure

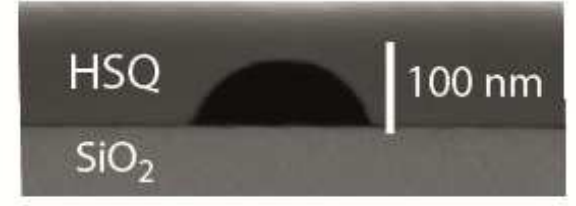

Extremely slow evaporation
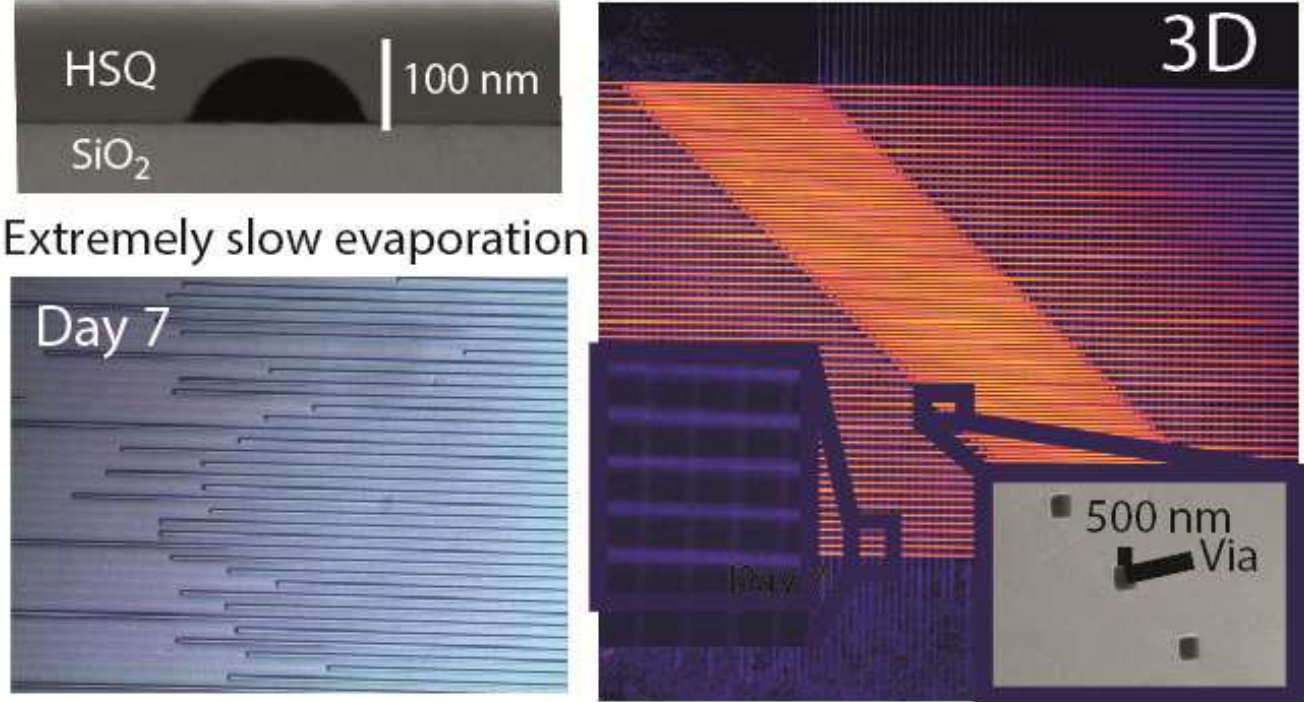

21

24

25

26

27

28

29

30

31

32

33

34

35

36

37

38

39

40

41

42

43

44

45

46 


\section{WILEY-VCH}

Copyright WILEY-VCH Verlag GmbH \& Co. KGaA, 69469 Weinheim, Germany, 2013.

\section{Supporting Information}

\section{Hydrogen Silsesquioxane-based Nanofluidics}

Sathyanarayanan Punniyakoti, Ragavendran Sivakumarasamy, Francois Vaurette, Pierre Joseph, Jean-Francois Dufreche, and Nicolas Clément*

\section{D prototyping of HSQ}

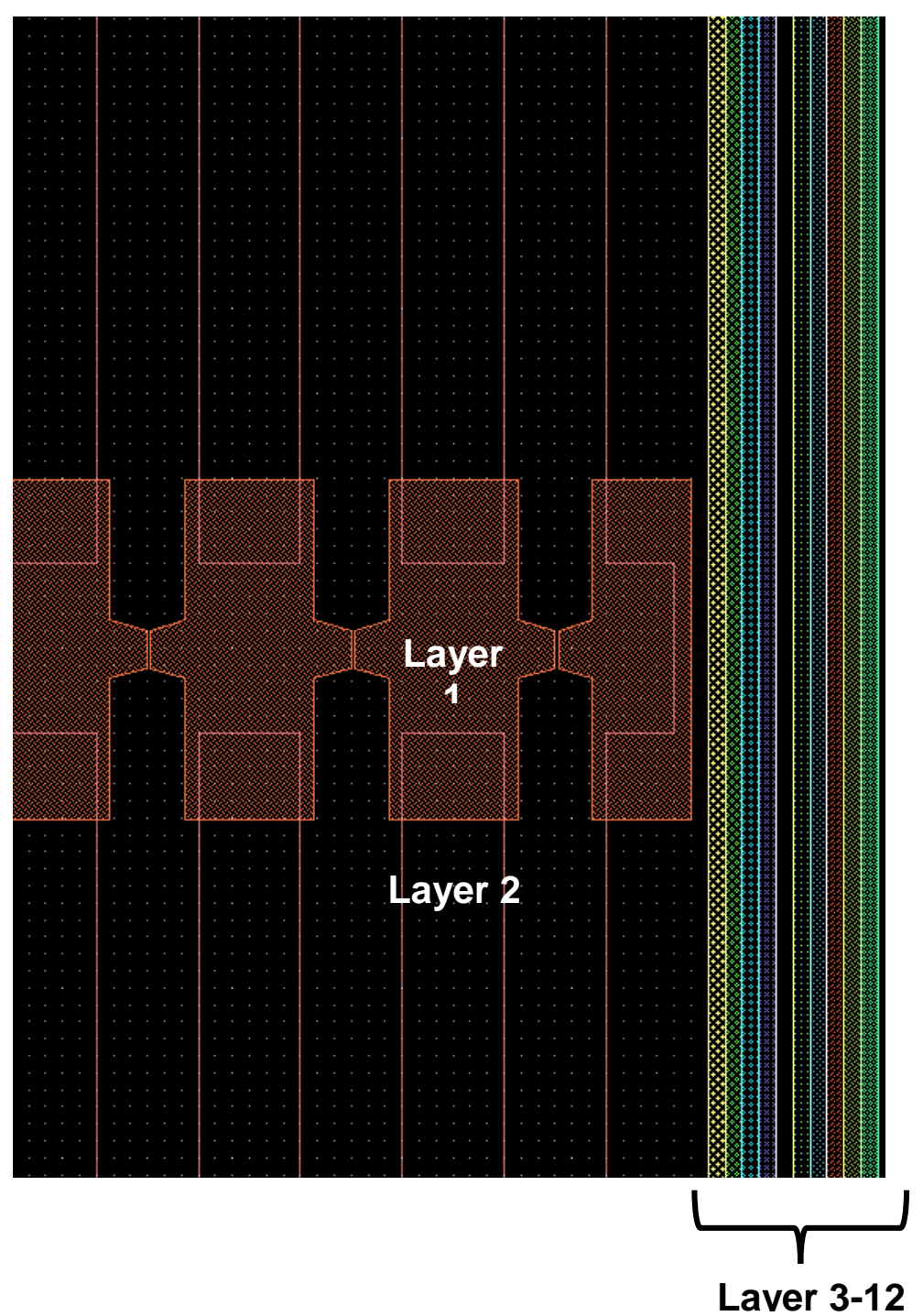

Supplementary Fig.1: Layout of the structure shown in Fig.1. Layer 1 is performed at High resolution, and layers 2-12: at low resolution. Doses in $\mu \mathrm{C} / \mathrm{cm}^{2}$ were $850,1000,900,800,750,700,650,600,575,550,525,500$ respectively. 


\section{WILEY-VCH}

1

Electron beam lithography: Raith EBPG 5000P

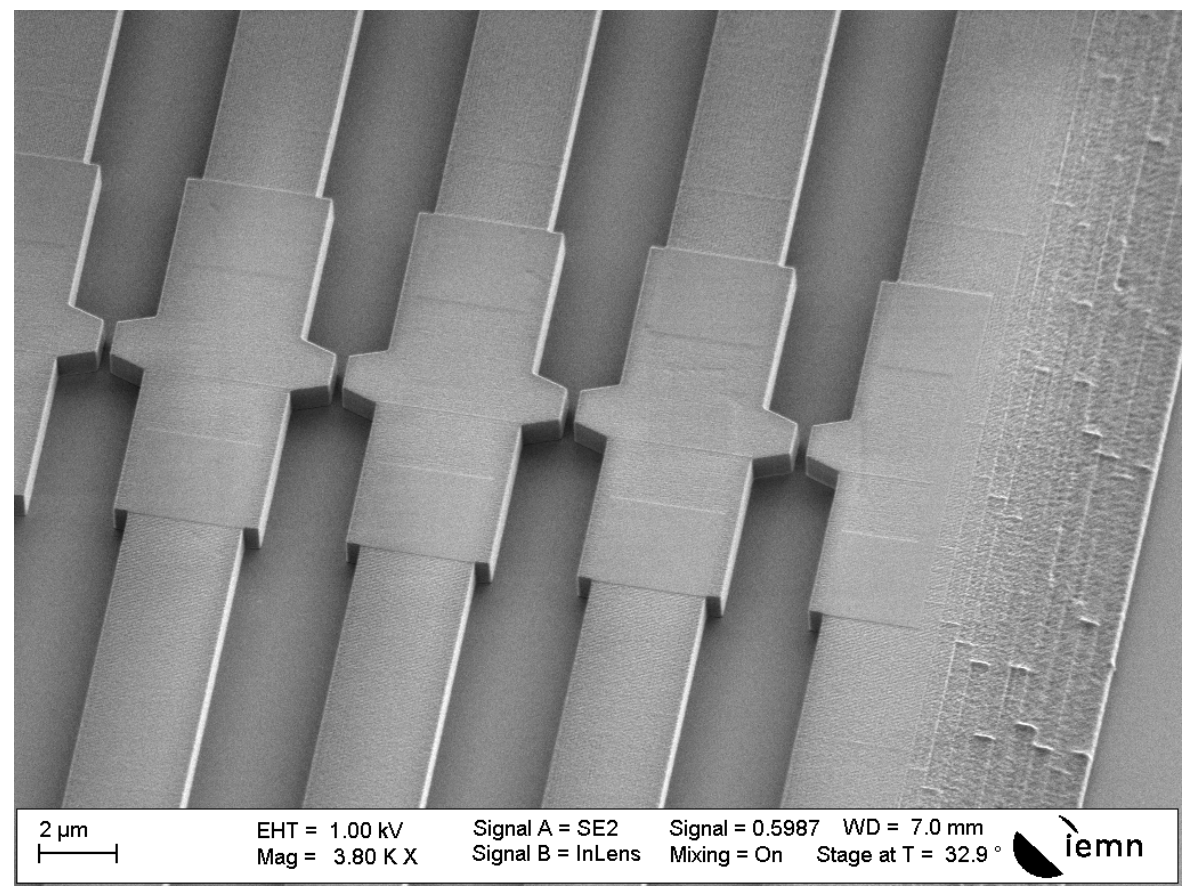

Supplementary Fig.2: E-beam lithography (Raith EBPG 5000P) corresponding to the layout shown in Supplementary Fig.1. 
WILEY-VCH
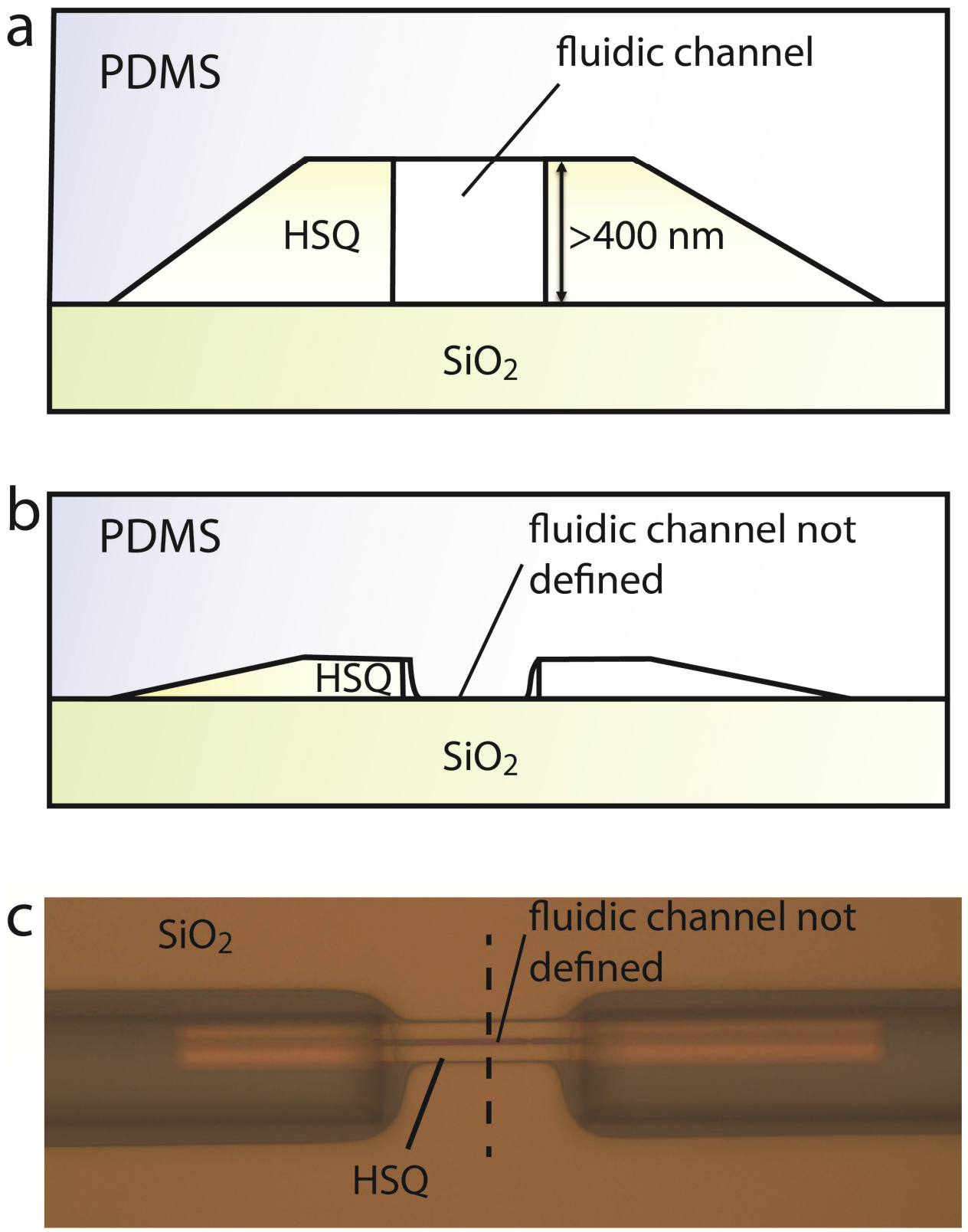

Supplementary Fig.3: Illustration of the minimum HSQ layer thickness required. a) Schematic representation of the efficient process when the HSQ layer thickness is above $400 \mathrm{~nm}$. The fluidic channel is well defined. b) Schematic representation of the process when a thin HSQ layer is used. The PDMS bonds in the channel and the fluidic channel is not defined. c) Optical microscope image corresponding to the schematic representation in b) for a $300 \mathrm{~nm}$ thick HSQ layer. 


\section{WILEY-VCH}

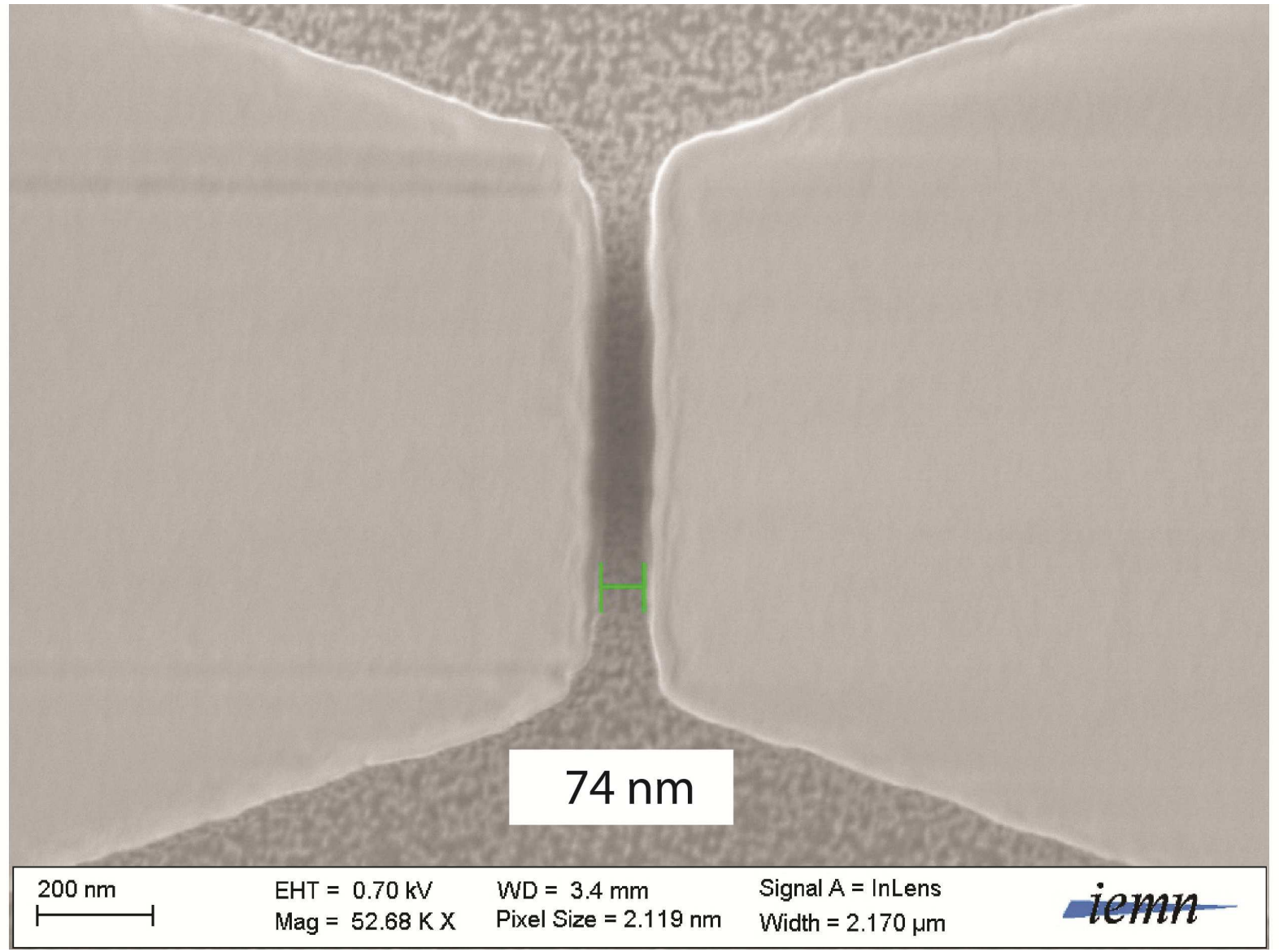

Supplementary Fig.4: Illustration of the minimum HSQ channel width obtained for an HSQ layer thickness of $850 \mathrm{~nm}$. 


\section{WILEY-VCH}
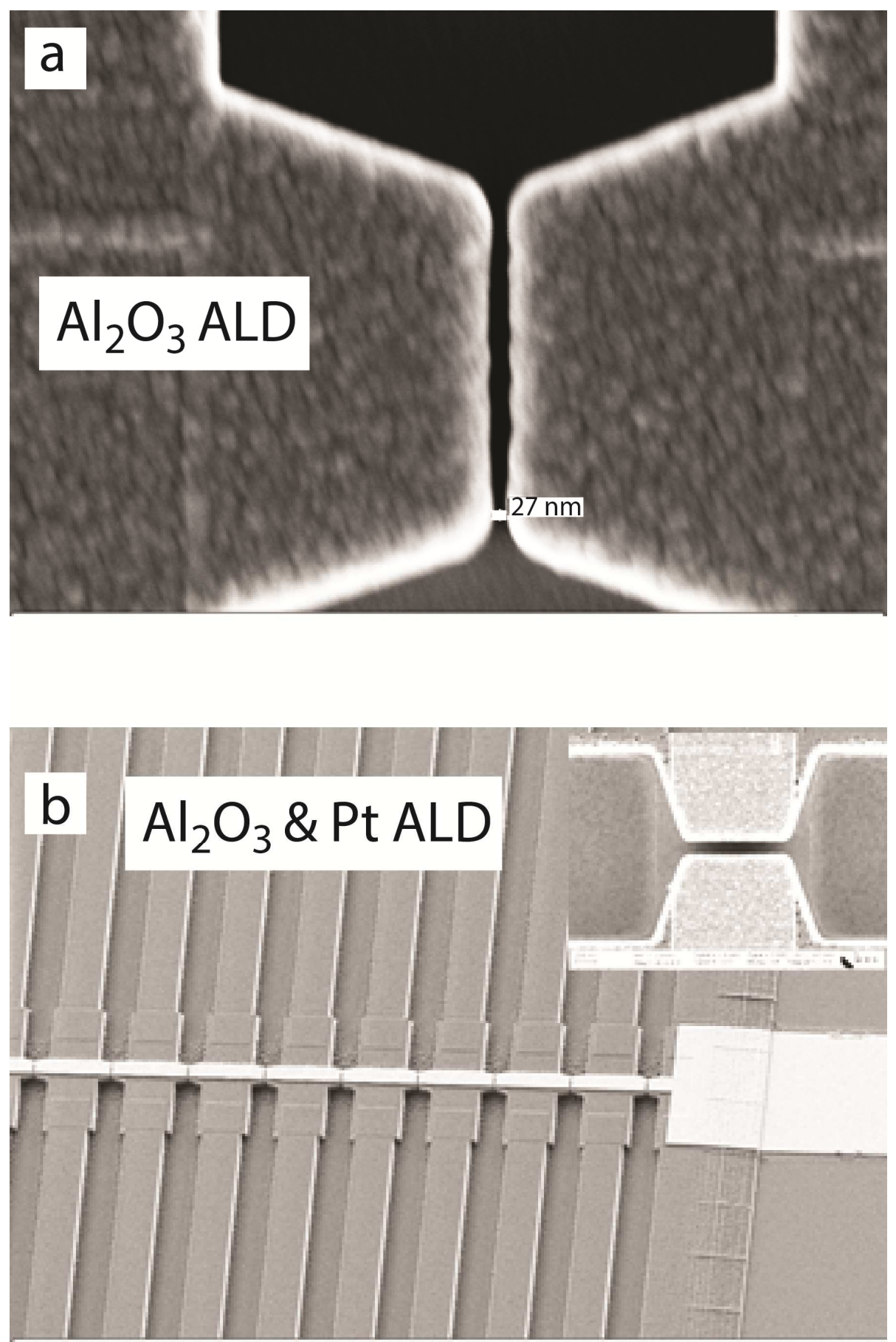

Supplementary Fig.5: Tuning channel width and properties using ALD. a) SEM image showing a channel $<30 \mathrm{~nm}$ obtained after $\mathrm{ALD}$ of $\mathrm{Al}_{2} \mathrm{O}_{3}$. b) SEM image of the nanofluidic channels composed of $\mathrm{HSQ} / \mathrm{Al}_{2} \mathrm{O}_{3} / \mathrm{Pt} / \mathrm{Al}_{2} \mathrm{O}_{3}$, which could be used for the development of vertical nanofluidic transistors. Inset: Top view image. 


\section{WILEY-VCH}
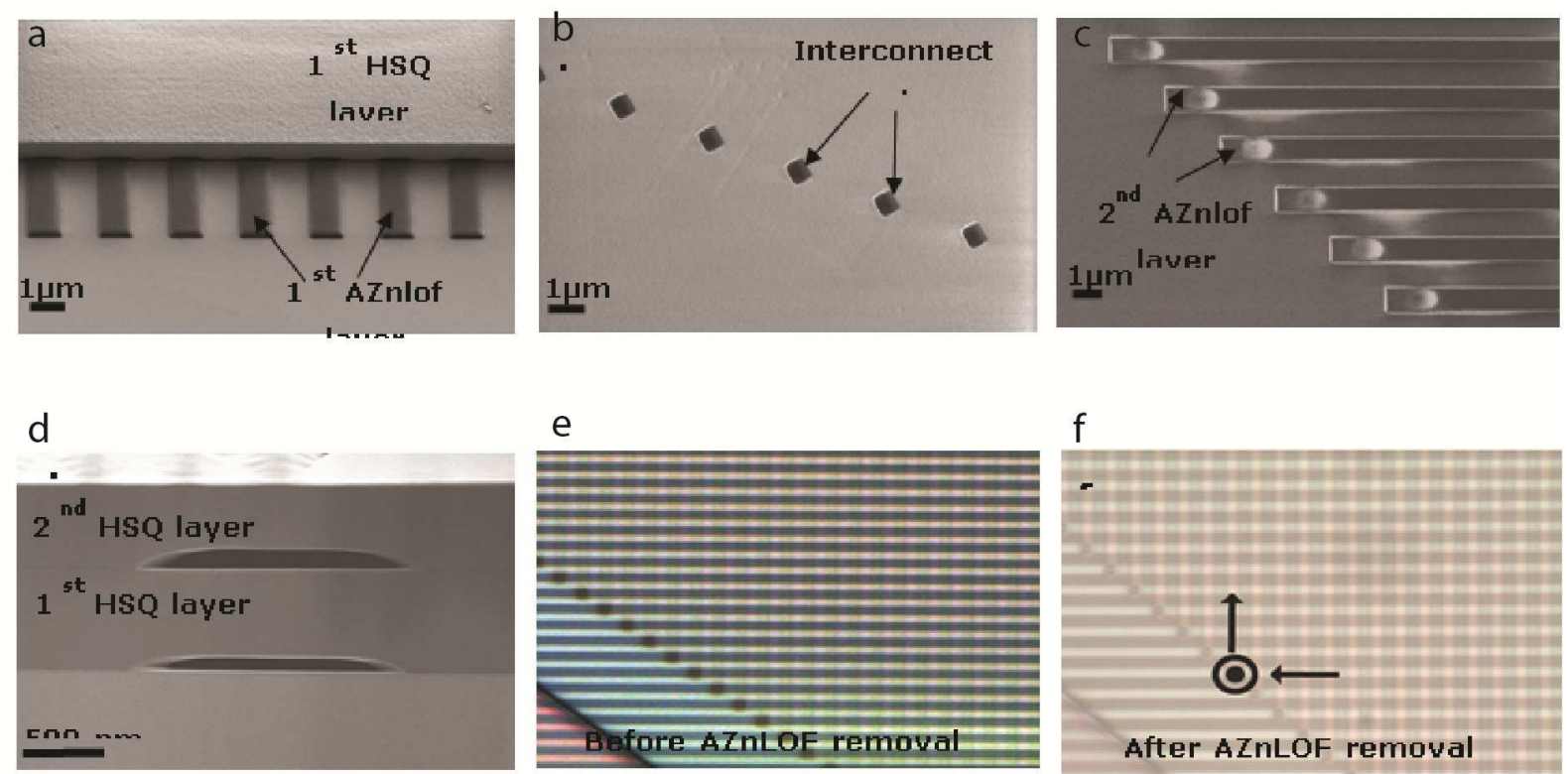

Supplementary Fig.6: Step-by-step explanation of the 3D HSQ nanofluidics. a) standard process for layer 1. b) Vias aligned on layer 1. c) Second layer of AzNLOF. d) Cross section image after 2 layers deposition (channels are tilted to their main axis to get both channels on the same cross section). e) Optical image before sacrificial layer removal. f) Optical image after AznLOF removal. 


\section{WILEY-VCH}

a
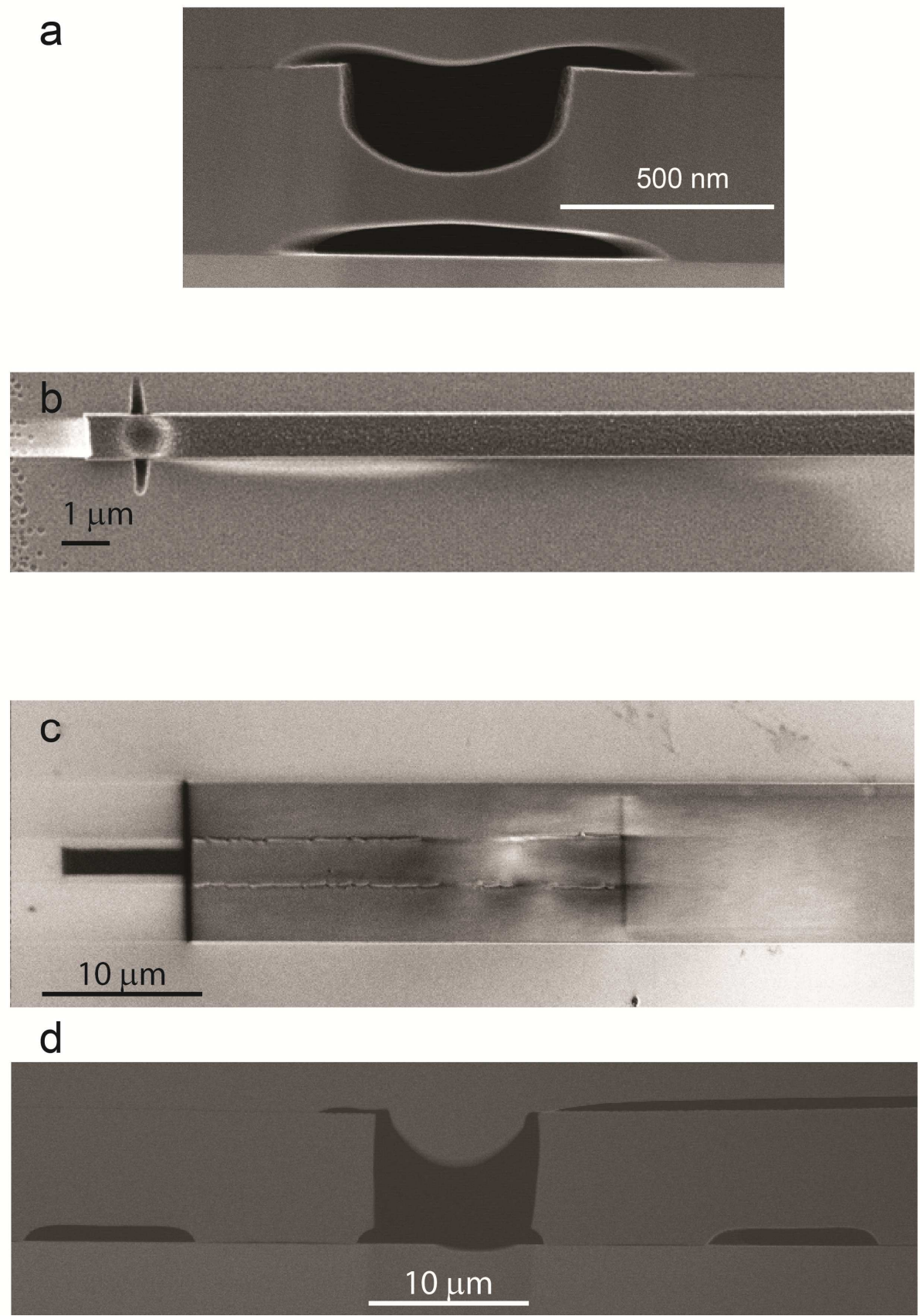

Supplementary Fig.7: Issues to be considered as design rules for (3D) HSQ nanofluidics. a) SEM image illustrating the difficulty of achieving a uniform etching of the via. b) SEM image showing a crack appearing in HSQ if the etching time is above the AznLof layer. c) SEM image showing the collapse of HSQ if the channel width is above $3 \mu \mathrm{m}$ or if the HSQ layer thickness is below $400 \mathrm{~nm}$. d) SEM image showing that the 2nd layer of AZnLOF can fall into the via, which can induce a clogging of the hole after HSQ deposition. A $500 \mathrm{~nm}$ large via is the best compromise. 